\title{
Vertical Features in Flux: Elevation, Interiority and the Anthropocene Disruption of South West Louisiana's Five Salt Dome Land Islands
}

\author{
Philip Hayward
}

University of Technology Sydney, and Southern Cross University, Australia

prhshima@gmail.com

\author{
Alahna Michele Moore
}

ammoore3@my.uno.edu

Publication Information:

Received 21 September 2018, Accepted 28 September 2018, Available online 31 December 2018

doi: 10.21463/jmic.2018.07.2.02

\section{Abstract}

While islands are clearly delineated from mainland locations by virtue of their encirclement by water, fixation on this element has led to an under-appreciation and related under-exploration of the comparability of islands to elevated terrestrial features such as hills, mountains and ridges. In this article we discuss the manner in which the five so-called salt dome 'islands' (SDIs) of south-western Louisiana exhibit a continuum of features across locations that range from an island (Belle) to a hill (Jefferson) with the remainder (Avery, Cote Blanche and Weeks) occupying positions within these dualities. Salt domes are landscape elements produced when areas of horizontal salt deposits are forced into the strata above, where they form dome shaped intrusions. Some of these distort the surface and protrude above flat areas of land as small hills. In the case of the five salt domes discussed in this article, their protrusion above the swamplands and drier flatlands of south-western Louisiana has resulted in their perception, identification and nomenclative representation as islands. In this article, we focus on the verticality and material spatiality of the SDIs and consider the ways in which their islandness has been effected by the commercial operations that have operated on/in them.

Particular focus is given to various mining and related underground storage enterprises that have disrupted the physical nature of the salt domes' subterranean spaces, the surface that covers them and surrounding land- and water-scapes. Verticality and interiority are identified as key - if often under-recognised - aspects of islandness in general and of the SDIs in particular.

\section{Keywords}

Verticality, Interiority, Louisiana salt dome islands, islandness, Island Studies 


\section{Introduction}

Following its commencement in the 1980s, the interdisciplinary field of Island Studies has gained considerable traction. Central to the field's raison d'être has been its identification of islands - its central and sole area of study - as distinct from other landforms. The field's stress on full aquatic encirclement as a defining aspect has been understandable, in this context, but also somewhat one-dimensional. We use the latter term in both literal and allusive senses. The 'islandness' that Island Studies concentrates on is one that can most easily be adduced from reference to maps (or to satellite images) or else from social perceptions of islandness that can be cross-referenced to these. Any given individual placed into any given location without prior knowledge of where they are can only be sure that they are on an island if they have a point of elevation sufficient to scan the entire coast of the landmass concerned; or if they can circumnavigate the island and thereby be assured of its status. In the latter regard, the encirclement model is a useful 'identity card' for geographical entities - i.e. if maps can show land areas as having perimeters encircled by marine, lacustrine or riverine waters they are, ipso facto, islands (just as any geographical entity that has a land connection, however slender and/or inaccessible, is not).

The shortcomings and implications of such unambiguous definitions have been challenged in recent years by journals such as Urban Island Studies (201x-), which has been inclusive enough to feature various types of non-traditional islands (such as, for example, population enclaves and urban spaces that have developed on former island sites). The journal Shima has also explored aspects of peninsular 'almost islandness' in a theme issue (v10n1) and in subsequent articles. But in addition to these expansions, there still a curious blind spot with regards to the defining characteristic of islands. Given that their encirclement by a fluid mass of a (relatively) constant height is their defining aspect, ${ }^{1}$ their elevation is clearly the key element that engenders their status as islands. In this regard, verticality is crucial and islands can be primarily understood as vertical features (rather than the flat cartographic silhouettes they are usually represented as). While Island Studies has never explored the topic, islands invite comparison to elevated terrestrial features such as hills, mountains and ridges, particularly when there are marked differences in habitat, population and/our resources between elevated areas and surrounding planes. ${ }^{2}$ This article explores a group of landscape features that transition between 'classic' islands and elevated terrestrial figures. The five salt dome islands (SDIs) of south-western Louisiana (Avery, Belle, Cote Blanche, Jefferson and Weeks) (Figure 1) rise between 20 and 46 metres above surrounding marshes and drier flatlands and range from a hill (Jefferson) through to an island (Belle) with the remaining three being elevated landscape features with varying degrees of encirclement by water.

This article examines the islandness of the five SDIs with regard to both orthodox understandings of the former term and with regard to their islanding within terrestrial environments. Based on the authors' fieldwork in south-western Louisiana in early 2016 and subsequent archival research, we set out to identify the manner in which the vertical mass of the protrusive salt domes is crucial to their identification as islands; to characterise and analyse the manner in which their surfaces and interiors have been exploited and inhabited; and to consider the effect of the latter on surrounding locales. As the following analyses identify, the five SDIs have fundamental aspects in common that render any attempts to distinguish them on the basis of the degree of their encirclement by water as pedantic rather than productive. In the case of the SDIs, the vulnerability of their physical structures and the permeability/integration of their interior structures within the surrounding water tables are their most apparent commonality and the various patterns of Anthropocene impact detailed below illustrate the fragility of their physical structures and their interior structures' vulnerability to inundation resulting from of resource excavation and/or inadequate structural reinforcement and/or remediation. 


\section{The Louisiana Salt Dome Islands}

The five SDIs profiled in this article are a subset of a broader scatter of such features across the landscape of the US Gulf Coast. The salt cores central to the SDIs' dome masses (Figure 2) were deposited from the shallow sea that covered the area in the middle Jurassic period. Subsequent alluvial deposits exerted pressure on the salt deposit layer, resulting in areas of both horizontal and vertical displacement (Schuster, 1995). One result of this process was the formation of diapirs (dome-like distortions formed by the upwards intrusion of one type of material into another). While the majority of the resultant diapirs in the region are sub-surface features, some appear at the surface level as low-lying, dome-shaped hills. The area around the Gulf of Mexico has one of the planet's highest known concentration of subsurface salt diapirs (around 500 having been identified to date). The five SDIs discussed below are notable for occurring in predominantly flat and often swampy locations. In this regard it is their elevation above surrounding terrain that has led to identification of their islandness by a succession of communities that have inhabited the area over the past three centuries, including the indigenous Atakapa-Ishak people (who referred to such landscape features as ka'k hidso'm [Gatschet and Swanton, 1932:42]) successive groups of francophone settlers and, most recently, anglophone settlers (see Hayward, 2016 for a study of social perception and related place naming in the region).

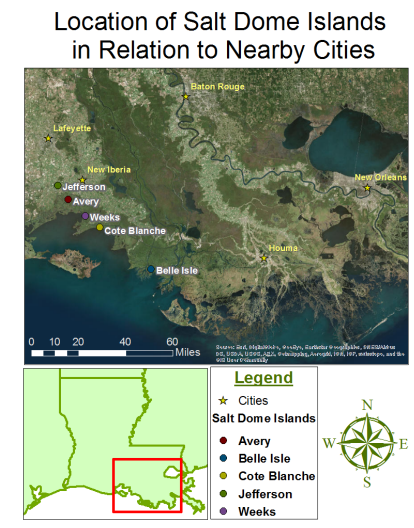

Fig 1. Map of location of the five salt dome islands (Moore, 2016)

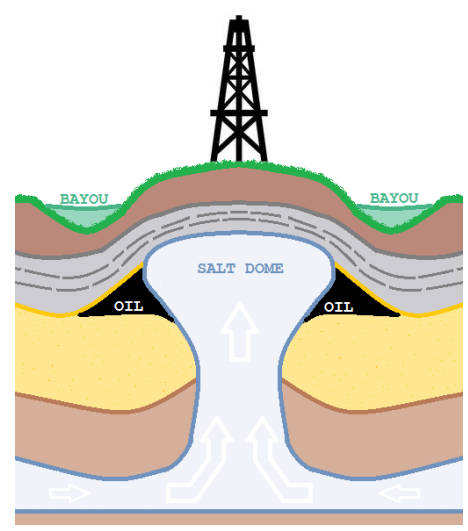

Fig 2. Typical salt dome hill structure (Moore) 
The five SDIs vary as to the nature of their islandness (within traditional definitions of that term). Jefferson Island is the least orthodox island in that it is a hill surrounded by farmlands, rising above these and being distinguished by woodlands on its slopes. Avery Island has more conventional island attributes, being accessed by a bridge over a canalised gully that encircles much of its elevated area. The canalisation of the gully occurred as part of the development of a network of waterways that resulted in the location shifting from being one that was periodically islanded, after periods of heavy rainfall, to one that was more permanently islanded as a result of dredging. Weeks Island can be accessed by roads at two points around a perimeter that is $90 \%$ surrounded by water. Cote Blanche is multiply islanded, being encircled by waterways and also being located on a narrow area of land separated from the mainland by the Gulf Intracoastal Waterway that runs between Texas and Florida. The SDI's main link to the adjacent mainland is by a car ferry that connects to a road off the main highway. Belle Island is the most stereotypical island of the group. It has no road access the bayous, canals and ponds that ring and intersect its lower slopes. As a private island it also has no regular ferries and visitors have to arrange their access in advance.

\section{Minerals and the Manufacture of Subterranean Spaces}

Of all things, modern humans tend to naturalise the ground, seeing the terrestrial platform beneath them as some immutable and natural product of geological processes working gradually over unimagineable time horizons. Such an understandable tendency leads to an overwhelming sense of ground as an inherently horizontal phenomenon - the very surface of the earth stretching to and beyond the horizon... Increasingly, the terrestrial material beneath our feet is anything but 'natural' geology: it is the vertically-accumulated phenomenon of manufactured ground. (Graham, 2016:np)

Salt domes are particularly attractive formations for mineralogical operations since they concentrate mineral resources close to the surface allowing for shallow access mining of an elevated area. Similarly, the distortion of sedimentary levels also traps natural gas and oil around the tops of the domes (Figure 2), allowing these deposits to be drilled with relative ease, creating areas of what Graham has termed "manufactured ground" (op cit).

While developments on each of the five SDIs have significantly disrupted native forest habitat and related fauna, the mineralogical exploitation of Jefferson Island has had the most striking impact on local topography. In 1980 oil drilling activity in Lake Peigneur, a body of water of an average 3.5 metres depth located to the immediate west of the SDI, penetrated the roof of an excavated area of the mine causing lake water to rush in, expanding the initial hole as it dissolved surrounding salt deposits and creating what is regarded the largest ever human-made sinkhole. The effects of the influx and of the widening of the initial small passage as water flowed in were dramatic. In addition to sucking the drilling rig, eleven large barges and a fishing boat into the subterranean cavern, it also resulted in permanent changes to the landscape, causing a 26 hectare area of Jefferson Island to subside into the lake, submerging trees and buildings. It also dropped the lake floor from 3.5 to 400 metres and changed its composition from a freshwater lake to a saltwater one as the sinkhole pulled water in from Delcambre Canal and Vermilion Bay via a (short-lived) 50 metre high waterfall (Warren, 2006:928-930). Despite this vivid illustration of the fragility of the cavern structure underlying the islands, areas of its excavated caverns now operate as natural gas storage facility run by AGL Resources that is connected to a regional distribution hub. 
While Weeks Island has not experienced subsidence and inundation on a scale similar to Jefferson's, the nature of its mining operation has posed a substantial threat to the local environment. Salt production commenced in the early 1900s. Initially the salt was conveyed off the island by motorised road transport but by the 1930s the operators started exploiting adjacent waterways to ship the product by barge to New Orleans. Morton Salt Company took over ownership of the island in 1947. Its mining operation and an associated chemical manufacturing facility resulted in the establishment of various amenities (such as housing, a general store and post office) in the centre of the SDI but all residents and were removed in 1969 when the mining company's insurers advised that there was a severe risk of surface subsidence. The evacuation highlighted that those residing and/or working on the island were not so much surface dwellers exploiting subterranean mineral assets in a stable environment as individuals perched, somewhat precariously, on the fragile dome of a complex, engineered cavern space constructed with little regard to its long-term stability and/or environmental impact.

Despite the precautionary measures undertaken on Weeks in 1969, the main mine site continued operating until 1977 when it was taken over by the federal Department of Energy (DoE). The DoE acquired the mine as a strategic petroleum reserve during a shortfall in global oil supply in the late $1970 \mathrm{~s}^{2}$ that caused the US to seek locations for strategic reserves. After a conversion process, the DoE commenced using excavated caverns underneath the surface of Weeks Island as crude oil storage facilities in 1980 (with Mortons also being allowed to operate an new excavation site nearby). The establishment of the facility led to the imposition of a security regime that effectively closed the SDI off to all but accredited employees. In 1992, a substantial sinkhole opened up on the edge of the oil reserve area (caused by freshwater dissolving salt around a fracture in the wall of the salt diapir), with the result that "fresh groundwater inflow directly into the mine threatened the environmental security of the facility, with the potential for driving the stored oil into the overlying sediments and to the ground surface" (Ehgartner and Musson, 2005:7). In the face of threat of major damage to Weeks Island's physical structure and environment-including potential sink holes-the facility was subsequently decommissioned, requiring a highly complex processes of draining the reserve and replacing the (accessible) oil with salt water (with the remainder left in inaccessible pockets).

Notwithstanding the decommissioning and attempted remediation, continuing subsidence and leakage issues continue to be apparent (see Warren, 2006:1136-1138) but the restriction of access to the site by outside observers has prevented detailed documentation of the extent and nature of problems occurring there. While the strategic oil reserve is no longer operative, the Dow Chemical currently have a processing facility on the SDI and both Dow and the salt mine maintain a similarly high level of security; with road access to Weeks restricted, prominent signage and security personnel actively monitoring all incoming traffic and inhibiting environmental monitoring by outside groups. (Illustrating this, a visit to the exterior of the salt mine's perimeter fence by the authors in March 2016 resulted in a rapid interception by a security employee and our ejection from the area.)

Given the problems encountered at Weeks, it is fortunate that one plan for Avery Island proposed in the 1950s did not gain traction. Awareness of the scale of the excavations of the SDI's salt deposits led to brief and controversial trials to ascertain whether its excavated cavern spaces might be suitable sites for the storage of nuclear waste. The first major research into this topic was undertaken by Heroy (1957), who identified that:

It is feasible to excavate in underground salt deposits reservoirs that are adequate to contain the volumes of liquid waste that are contemplated in a program of development of nuclear power. However, the waste stored in such reservoirs would soon, from its own energy, rise in temperature to the boiling point, creating an additional hazard of production of radioactive vapor. (1957:13.7) 
But the report also went on to conclude that, "no insurmountable obstacles to the storage of radioactive waste in solid form in underground cavities in salt appear to exist" and called for research on economic aspects and engineering logistics (including the issue of transforming liquid waste into solid form) (ibid:14).

Similar perceptions of the safety of solid storage led to the establishment of the world's first sub-surface radioactive waste facilities in disused salt mines in Germany in 1967 and $1971,{ }^{3}$ both of which operated until deterioration of the salt domes and concern about pollution leakage led to their closure. Informed by the German initiatives and Heroy's abovementioned report, the US DoE supported the establishment of similar radioactive waste storage facilities near Carlsbad in New Mexico in 1973, which finally commenced operation in 1999, after two decades of opposition led by the New Mexico Environmental Evaluation Group (whose research suggested that the site was far less safe than official sources suggested). The protracted duration of the establishment process indicates the degree of public concern about such storage activities and was mirrored in Louisiana when the state's salt domes were also identified as potential sites for radioactive waste storage. In the mid-1970s the Vacherie (sub-surface) salt dome, located outside Shreveport (in north-western Louisiana) was identified as a potential storage site. Concerted action by local activists proved more successful than in New Mexico, turning public and state government opinion against locating a site in the state. Fortunately for environmental activists, a set of preliminary tests conducted by Union Carbide in Avery Island's salt mine caverns in 1979-82 showed various potential problems related to brine migration arising from storage of heat generating radioactive materials (Hansen and Leigh, 2011:8) and inclined the company not to pursue such developments. As a result of Union Carbide's own assessments and long-term, entrenched opposition to nuclear waste storage, the Louisiana state legislature passed legislation in 2011 that specifically prohibited disposal of radioactive waste in salt domes (RS 30:2117), delivering a rare victory for environmental activism in the region.

Belle Isle's recent history combines elements of the various aspects explored above. While the island was initially exploited for timber extraction and sugar cane cultivation, in 1941 Sun Oil commenced a commercial extraction site that soon became one of the state's highest-producing oil operations. The Cargill company also commenced salt mining on the island in 1962. Despite awareness of potential safety problems (Morris, 2008:2), Cargill did not address these and when an underground fire broke out in 1968, following a schedule sub-surface explosion, all 21 workers trapped underground by it died. Despite this, salt mining continued until 1984 when structural problems with the underground cavity caused the company to cease its operations on the island. In order to address these problems and decommission its operation, the company dug a channel to guide saltwater to a minehead and then set off an explosion that caused water to gush in and fill excavated areas of the dome space, altering the nature of water-flow patterns around the island and creating a deep water space adjacent to it. Since the mine's explosive decommissioning, Belle Isle has been the first (and only) salt dome site to experience significant de-industrialisation and related habitat restoration planning (at least in terms of its salt mines - oil wells still operate in some areas). The current owners of the island have acknowledged the need for restorative work and have formed a company to pursue this. Along with restitution of native habitat, the company's (undated) 'Vision Statement' identifies the coast of the island and its points of interface with surrounding waterways as a priority. Along with categories addressing "Property Protection" (addressing "any additional environmental or physical damage from the activities that will occur in the future exploration or mining activities") (ibid), a further category entitled "Environmental Enhancement" has the stated goal to:

Restore the property to its natural state. This will be accomplished by looking at the property to determine areas in which land loss has occurred. We will then determine if there are mitigation projects that can be done in order to restore the property back to its natural state ... Research will need to be completed on the 
determination of the boundaries of the property and the ownership of water bottoms. This will include the boundaries to the south and west along with Belle Isle Lake. (ibid)

The aim of restoring the island "back to its natural state" is vague and tendentious, as the precise point and nature of the "natural state" referred to is unclear and the landscape and waterways surrounding the island have been altered by human engineering in a manner that makes restoration highly complicated. Even if such a project could be realised, rising sea levels resulting from human impacts on the global climate are likely to further modify the dry areas of the island by submerging its low spots seasonally and more generally.

\section{Discussion}

In a response to Elden's 2013 essay 'Secure the Volume', Bridge characterised the manner that the "qualities of space... above on the surface, and below underground - are radically different" (2013:55) and went on to identify that:

The combination of profoundly different spatial realms with the possibility of establishing connection between them lends tunnels, holes and other vertical structures an important creative-destructive potential. (ibid:56)

Developing this characterisation with regard to Mumford (1934), Bridge asserts that "the shock of modernity" is, at least in part, due to

The radical mixing together of these two different planes. The sense of vertical rupture and displacement is, I suggest, at the heart of the concept of the Anthropocene: the anthropogenic eruption of the underground over the last 250 years, and the impact of this raid on the lithosphere. (ibid)

Bridge's characterisation of the "shock" of modernity resulting from the "creative-destructive potential" of subterranean engineering, resource extraction and associated collateral "ruptures and displacements" is particularly apposite for consideration of the recent history of the five SDIs profiled in this article. For all their apparent monumental stability in the Louisiana landscape, the crises, accidents and attempted remediations of interior dome spaces and of the areas surrounding them have underlined the manner in which their vertical engineering and exploitation has been the most significant aspect of their recent pasts and presents. The identification of the SDIs as islands is premised on an aspect of their verticality, i.e. their elevation above surrounding flats and the waterways that wind around them, but the height of these elevations are miniscule in proportion to the depth of the mines that have been constructed within their dome spaces. While their surface elevation has created their islandness and attracted distinct patterns of human perception, settlement and/or exploitation, far more of the diapirs are beneath the surface than emerge above it. Similarly, there is far more industrial activity, pollution and incidental structural disruption and damage in interior rather than exterior levels; meaning that the subsurface activity is a crucial area for environmentalists to monitor, respond to and to strategise about. 


\section{Conclusion}

Since its inception, Island Studies has primarily regarded islands as encircled surfaces. This article, by contrast, has sought to emphasise the verticality and interior spatiality of the five south-western Louisiana SDIs with particular regard to their complex natural and human-engineered aspects. The relatively peculiar nature of their form (and of their local perception and identification as islands) is not in dispute but it is our contention that consideration of them-in all their marginality and liminality-is useful in identifying the need for both Island Studies and Geography more generally to recognise the fundamental connections between and comparability of islands and elevated terrestrial features. While most of the SDIs discussed above are not located within open water environments, their internal masses, strata and/or excavated spaces interconnect with and are implicated within water-tables and/or riverine and lacustrine systems in manners that can be considered as just as definitive of their islandness as the clearly delineated shores of Belle Island. Similarly, we can observe that the livelihood activities conducted within and with regard to such aquatic features are as definitive of island spaces and communities as interactions conducted across their terrestrial/aquatic shorelines.

\section{Acknowledgments}

Research for this article was conducted by the first author in 2016 during a visiting research scholarship at the Midlo Center for New Orleans Studies at The University of New Orleans, where the second author was a Masters student in Urban Studies. Thanks to Connie Zeanah Atkinson for facilitating this project; to Wilma Subra for assisting our research and giving us feedback on the first draft of this paper; and to Jeffery Darensbourg, Tribal Councilperson and Alligator Band Head, Atakapa-Ishak Nation of Southwest Louisiana and Southeast Texas, for his insights into the indigenous history of the region. As will be apparent, our approach has been significantly influenced by Steve Graham's work on aspects of verticality, many thanks to him for giving us access to the manuscript of his book on the topic prior to its publication. Also thanks to Craig Colten and to Christian Fleury for additional assistances.

\section{Endnotes}

1. As is evident in the case of low-lying islands that are increasingly prone to inundation in the Anthropocene era and - thereby - their 'de-islanding."

2. Island Biogeography has recognised this aspect, regarding areas such as mountain peaks, mountain valleys etc. as effectively 'islanded' by their topography (see, for instance, Whittaker and Fernandez-Palacios (2007).

3. Caused by the drop in volume of Iranian exports following the revolution that brought the Ayatollah Khomeini to power in 1979.

4. In the Asse Mountains of Lower Saxony in 1967-78 and in Morsleben in 1971-91. 


\section{References}

Belle Isle LLC Website (undated): http://www.belleislellc.com/Belle_Isle/Mission_Statement.html

Bridge, G 2013. Territory, now in 3D! Political Geography 34. 55-57.

Brown, I, 1991. Salt manufacture and trade from the perspective of Avery Island, Louisiana. Midcontinental Journal of Archaeology 24. 113151.

Ehgartner, B and Musson, D, 2005. Final Report on Weeks Island Monitoring Phase - 1999 through 2004. Sandia National Laboratories, Albuquerque.

Elden, S, 2013. Secure the volume: Vertical geopolitics and the depth of power. Political Geography 34. 35-61.

Gatschet, A and Swanton, J, 1932. Dictionary of the Atakapa language. Washington DC: Smithsonian Institute. Retrieved from https://texashistory.unt.edu/ark:/67531/metapth20200/m1/74/

Graham, S, 2016. Vertical Ground: Making Geology - keynote address to Island Cities Conference, University of Hong Kong 7 March 2016.

Graham, S, 2016. Vertical: The City from Above and Below. Verso, London.

Hansen, F and Leigh, C, 2011. Salt Disposal of Heat-Generating Nuclear Waste Sandia National Laboratories, Albuquerque.

Hayward, P 2016. Enduring Perceptions: Place naming and the perception of Louisiana's salt dome islands. Island Studies Journal 11 (2). $417-$ 430

Heroy, H 1957. Appendix F: Disposal of Radioactive Waste in Salt Cavities in Report prepared for the Committee on Waste Disposal in Geologic Structures Website: http://www.ncbi.nIm.nih.gov/books/NBK208696

Morris, G, 2009. Belle Island Tragedy. The Advocate March 9: http://tinalation.net/uploads/3/1/8/5/3185139/cargill_2008advocate.pdf Mumford, L, 1932. Technics and Civilisation. New York: Harcourt Brace

Schuster, D.C 1995. Deformation of allochthonous salt and evolution of related salt-structural systems, Eastern Louisiana Gulf Coast. In Jackson, M.P.A., Roberts, D.G. and Snelson, S, (eds) Salt tectonics: a global perspective, AAPG Memoir 65. 177-198

State of Louisiana, 2011. Revised Statute 30:2117 - Radioactive waste disposal; prohibition of disposal of radioactive wastes in salt domes; salt dome usage

Strauss, B, Kulp, S, and Levermann, A, 2015. Carbon choices determine US cities committed to futures below sea level. Proceedings of the National Academy of Sciences of the United States of America 112. 13508-13512

Warren, J 2006. Evaporites: Sediments, Resources and Hydrocarbons. Berlin: Springer 